\title{
Hospital admissions before and after shipyard closure
}

\author{
Lars Iversen, Svend Sabroe, Mogens T Damsgaard
}

\begin{abstract}
To determine the effect of job loss on health an investigation was made of admissions to hospitals in 887 men five years before and three years after the closure of a Danish shipyard. The control group comprised 441 men from another shipyard. The information on hospital admissions was obtained from the Danish national register of patients. The relative risk of admission in the control group dropped significantly in terms of the number of men admitted from the study group from 1.29 four to five years before closure to 0.74 in the three years after closure. This was especially true of admissions due to accidents $(1.33$ to 0.46$)$ and diseases of the digestive system (4.53 to 1.03$)$. For diseases of the circulatory system, particularly cardiovascular diseases, the relative risk increased from 0.8 to 1.60 , and from 1.0 to 2.6 respectively.

These changes in risk of illness after redundancy are probably a consequence of a change from the effects of a high risk work environment to the effects of psychosocial stresses such as job insecurity and unemployment.
\end{abstract}

\section{Introduction}

Closures of factories entail a process that has different stresses in different phases. Usually there is a period during which the fate of the company is uncertain. The threats of job loss and unemployment then gradually become more of a reality. In the phase after the closure many employees experience short or long periods of unemployment. Others find new but perhaps inferior jobs with lower wages, fewer opportunities for advancement, and little job security.

The results of several studies show reduced psychological well being and various symptoms of stress in both the insecure phase ${ }^{\prime}$ and, especially, the phase after a closure.$^{23} \mathrm{Kasl}$ and Cobb showed physiological effects, such as changes in blood pressure and in serum concentrations of uric acid and cholesterol, in their classic study of a company closure in the United States at the end of the 1960s. ${ }^{4}$ In a Swedish study Arnetz et al found that the immune system of women was affected by long term unemployment after a closure. ${ }^{5}$

Beale and Nethercott conducted a study of 129 employees and their families after a company closure in England in 1982, which showed increases of $20 \%$ in the number of consultations with general practitioners and $60 \%$ in the number of visits to outpatient departments. In a further analysis of morbidity four years after job loss they showed that the incidence of chronic complaints - defined as those requiring active management after one year-was more than six times higher in the men who had experienced job loss than in the control group. Cardiovascular disorders were often detected in the unemployed men, and several of the other chronic complaints from which they suffered may also have had psychosomatic aetiology related to stress.

Westin et al carried out a study of the effects of the closure on a Norwegian sardine factory in 1975. They found that the cumulative rates of disability pension granted for medical conditions were more than three times higher in the study group than in the control group from the second to the fourth year of follow up, after adjusting for sex, age, and sick leave in the year before the start of the follow up. ${ }^{8}$ Their data also showed that the closure had certain effects on health. The health measure used (disability pension granted for medical conditions), however, is not an unambiguous measure of somatic illness. A rise in pension rates could indicate that people with health problems have particular difficulties in finding new jobs and that the disability pension could be some sort of gateway to economic security.

In recent years Denmark has had one of the highest rates of unemployment in Western Europe. Since the beginning of the $1980 \mathrm{~s}$ an average of $8-10 \%$ of the work force has been without work. Nearly one in four wage earners is unemployed at least once a year. More than half of the unskilled workers experience periods of unemployment every year. Shipbuilding is one of the industries that has been particularly hard hit by structural changes and company closures. More than half of the shipyards' workforce has been made redundant over the past 10 to 12 years.

In 1983 one of the largest Danish shipyards, Elsinore shipyard, was closed. With a view to studying the health effects of this event a longitudinal study was started in 1983. It covered male employees from Elsinore shipyard (the study group) and a control group of male employees from Dannebrog shipyard, which is in another part of Denmark and was operational throughout the entire study. The figure shows how the closure resulted in a large number of men in the study group being made unemployed. Also in the

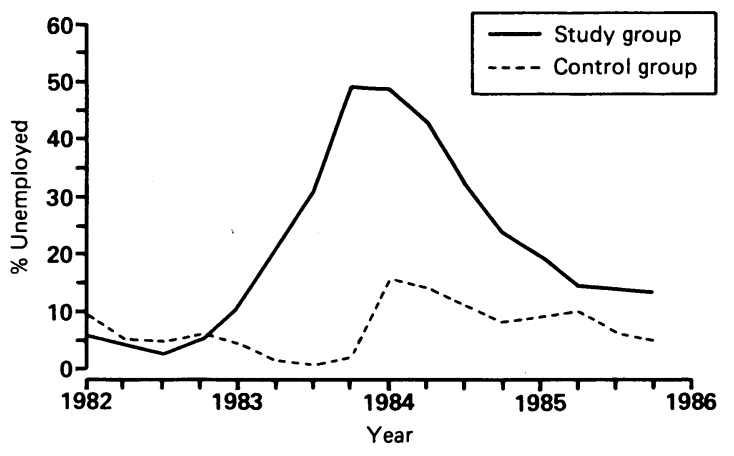

Unemployment in study group ( $n=887)$ and control group $(n=441)$, 1982-6

year of the closure (1983) a number of men in the control group were made redundant. Results from this study on the effects of unemployment on psychological well being, psychosomatic symptoms, and social network have been published elsewhere. ${ }^{39} 10$

We have studied the development of the number of hospital admissions over an eight year period (1979-86) to determine whether the closure affected admission patterns in the study group and thereby describe indirectly changes in morbidity. Our general expectation was that the closure would lead to a greater increase in the number of admissions of men in the study group than in the control group. Furthermore, on the basis of other studies we chose to study in detail admissions due to illnesses that may have been related

Iversen. 
to stresses resulting from the closure and subsequent unemployment, this being the case for cardiovascular diseases. ${ }^{11 \cdot 14}$

\section{Subjects and methods}

The study group consisted of 887 men employed at Elsinore shipyard in 1982 who had been there for at least six months. The control group consisted of 441 men employed at Dannebrog shipyard in the autumn of 1983. These groups comprised those men who replied to a self administered questionnaire (the participation rate was $67 \%$ for the study group and $82 \%$ for the control group) in November 1983 and who at that time were either at work or unemployed. (Men who had retired (85), were studying (24), or were not economically active (12) were not included.)

Table I shows the background characteristics of the groups in 1983. The two groups did not differ to any great extent in sex, occupation, marital state, self reported longstanding health problems, and smoking. In the study group, however, there were considerably more men aged 50-59 than in the control group. Adjustments for this difference between the two groups were made in the analyses. The table also shows that in 1982 the average rate of unemployment was nearly the same in the two groups and that it was considerably higher in the study group in the two years after the closure in 1983.

Data on hospital admissions were obtained from the Danish national register of patients for the years 1979 86. The register covers the whole of Denmark and contains information on the total number of admissions to Danish somatic hospitals in a designated time period, irrespective of any geographical moves in the population. Admissions to mental hospitals are not included in the register. Men with psychiatric disorders were therefore included only if they had been admitted to somatic hospitals. Data were collected only for those men who in 1983 answered the self administered questionnaire as the data surveillance authority did not permit the release of data regarding non-responders' admissions. The diagnoses at discharge were classified according to the International Classification of Diseases (8th revision). The hospital registration of admissions

TABLE I-Background characteristics of Danish men working in shipyards in 1983

\begin{tabular}{|c|c|c|c|}
\hline & $\begin{array}{l}\text { Study group } \\
\quad(\mathbf{n}=887)\end{array}$ & $\begin{array}{l}\text { Control group } \\
\qquad(\mathrm{n}=441)\end{array}$ & $\mathrm{p}$ Value \\
\hline \multicolumn{4}{|l|}{ Age (years): } \\
\hline$\leqslant 49$ & 607 & 368 & \\
\hline 50 & 257 & 63 & $<0 \cdot 01^{\star}(\mathrm{df}=2)$ \\
\hline$\geqslant 60$ & 23 & 10 & \\
\hline \multicolumn{4}{|l|}{ Marital state: } \\
\hline Married/cohabiting & 644 & 306 & $0 \cdot 96^{\star}$ \\
\hline Single/divorced/widowed & 212 & 100 & \\
\hline No who reported longstanding health problems & 293 & 131 & $0 \cdot 25^{\star}$ \\
\hline Smokers & 588 & 276 & $0 \cdot 16^{\star}$ \\
\hline \multicolumn{4}{|l|}{ Average unemployment (months): } \\
\hline 1982 & 0.60 & $0 \cdot 84$ & $0.01 \dagger$ \\
\hline 1983 & $3 \cdot 82$ & 0.46 & $0.01 \dagger$ \\
\hline 1984 & $4 \cdot 22$ & $1 \cdot 41$ & $0.01 \dagger$ \\
\hline 1985 & 1.88 & $0 \cdot 89$ & $0.01 \dagger$ \\
\hline
\end{tabular}

$\star \chi^{2}$ test. $\dagger t$ Test.

TABLE II - Number of admissions for men in study (887) and control group (441) before closure (1979-80), during closure (1981-3), and after closure (1984-6) of shipyard

\begin{tabular}{|c|c|c|c|c|c|c|}
\hline \multirow{2}{*}{$\begin{array}{c}\text { No of } \\
\text { admissions }\end{array}$} & \multicolumn{3}{|c|}{ Study group } & \multicolumn{3}{|c|}{ Control group } \\
\hline & $1979-80^{\star}$ & $1981-3 \dagger$ & 1984-6ł & $1979-80^{\star}$ & $1981-3 \dagger$ & 1984-6‡ \\
\hline 0 & 746 & 718 & 705 & 394 & 364 & 330 \\
\hline 1 & 117 & 117 & 113 & 37 & 46 & 75 \\
\hline 2 & 21 & 33 & 35 & 9 & 21 & 20 \\
\hline 3 & 2 & 16 & 13 & 1 & 5 & 6 \\
\hline$\geqslant 4$ & 1 & 3 & 21 & & 5 & 10 \\
\hline
\end{tabular}

$\chi^{2}=7 \cdot 43, \mathrm{df}=4, p=0 \cdot 11 .+\chi^{2}=6 \cdot 64, \mathrm{df}=4, p=0 \cdot 16 . \neq \chi^{2}=4 \cdot 89, \mathrm{df}=4, p=0 \cdot 30$ and diagnoses was performed on the same routine basis and was thus independent of this study. The analyses presented in this article are based solely on the main diagnosis recorded at discharge.

Following the methods of Beale and Nethercott ${ }^{7}$ we divided the study period into three phases: 1979-80 was the secure phase during which there was no mention of a closure at the shipyard; 1981-3 was the insecure phase during which rumours about a closure were rife. This phase also included the actual closure, which became a reality late in 1983 . The redundancies at the yard occurred over a period of time, and because of this the rate of unemployment in the study group never exceeded $55 \%$. The final phase covered the period 1984-6, the years directly after the closure.

As a measure of the admission pattern we calculated the number of men admitted to hospital per 1000 observation years for each of the three phases (repeated admissions counting only once). This can be considered as a measure of admission rate in each phase. The number of observation years was adjusted for ad missions, deaths, and emigrations from Denmark. The admission rates in the two groups were compared by estimating the relative risk of admission in the study group in relation to the control group. The relative risk was age adjusted following the method used by MantelHaenszel. ${ }^{15}$ Age was dichotomised at $<49$ and $\geqslant 50$ years.

\section{Results}

Table II shows the distributions of men according to the numbers of admissions in the two groups. No significant differences were seen in any of the three phases. Table III shows the admission rates for al diagnostic groups and for four selected diagnostic groups. The rate in the study group for all admissions fell from 85.0 per 1000 observation years in the first phase to 70.2 and 74.5 in the second and third phases respectively. In the control group the admission rate increased from $56 \cdot 2$ to $96 \cdot 5$. Our expectation that the closure would lead to an increase in the rate in the study group compared with that in the control group was clearly refuted. The relative risk of admission fell from $1 \cdot 29$ to $0 \cdot 74$. Table III also shows that this decrease was a result of different changes in different diagnostic groups. The table includes the two groups of diseases that we consider are related to stress (diseases of the circulatory system and the digestive system) and two diagnostic groups that are related to the work environment (musculoskeletal diseases and accidents) Furthermore, these four diagnostic groups comprised an adequate number of men admitted to hospitals to allow estimates of risk to be calculated. The rate of admissions to hospitals of people who were suffering from diseases in the circulatory system rose in the study group from 5.7 to 13.9 . The corresponding change in the control group was from $5 \cdot 7$ to $7 \cdot 7$. The relative risk therefore increased from 0.8 to 1.60 .

Diseases of the circulatory system is a rather broad diagnostic group that includes several illnesses that do not have stress as an aetiological factor. We therefore also analysed admissions specifically due to hypertension, ischaemic heart disease, and symptomatic heart disease (ICD codes 401, 410-14, 427). The most common diagnosis was acute myocardial infarction. In the study group the admission rate in the secure phase for this diagnostic subgroup was $2 \cdot 3$ (four cases), in the insecure phase $2 \cdot 3$ (six cases), and in the phase after closure 8.0 (21 cases). Corresponding figures for the control group were $2 \cdot 3$ (two cases), $3 \cdot 8$ (five cases), and $3 \cdot 1$ (four cases). The relative risk was $1.0(95 \%$ confidence interval 0.2 to 5.4 ) in the secure phase and $2.6(0.9$ to 7.7$)$ in the phase after the closure.

In the secure phase admissions due to illnesses of the 


\begin{tabular}{|c|c|c|c|c|c|c|}
\hline \multirow[b]{2}{*}{ Disease (ICD code) } & \multicolumn{2}{|c|}{ No of men admitted } & \multicolumn{2}{|c|}{$\begin{array}{l}\text { No of men admitted per } \\
1000 \text { observation years }\end{array}$} & \multirow[b]{2}{*}{$\begin{array}{l}\text { Relative risk } \\
\text { (age adjusted) }\end{array}$} & \multirow{2}{*}{$\begin{array}{l}95 \% \text { Confidence } \\
\text { interval of } \\
\text { relative risk }\end{array}$} \\
\hline & $\begin{array}{l}\text { Study } \\
\text { group }\end{array}$ & $\begin{array}{l}\text { Control } \\
\text { group }\end{array}$ & $\begin{array}{l}\text { Study } \\
\text { group }\end{array}$ & $\begin{array}{l}\text { Control } \\
\text { group }\end{array}$ & & \\
\hline \multicolumn{7}{|l|}{ All diseases: } \\
\hline $1979-80$ & 139 & 47 & $85 \cdot 0$ & $56 \cdot 2$ & $1 \cdot 29$ & $(0.87$ to 1.90$)$ \\
\hline $1981-3$ & 169 & 87 & $70 \cdot 2$ & $63 \cdot 7$ & 1.04 & $(0.79$ to 1.36$)$ \\
\hline $1984-6$ & 172 & 111 & $74 \cdot 5$ & $96 \cdot 5$ & $0 \cdot 74$ & $(0.58$ to 0.94$)$ \\
\hline \multicolumn{7}{|c|}{ Diseases of circulatory system (400-458): } \\
\hline $1979-80$ & 10 & 5 & $5 \cdot 7$ & $5 \cdot 7$ & $0 \cdot 8$ & $(0.27$ to $2 \cdot 39)$ \\
\hline $1981-3$ & 25 & 9 & $9 \cdot 5$ & 6.9 & $1 \cdot 04$ & $(0.48$ to $2 \cdot 25)$ \\
\hline $1984-6$ & 36 & 10 & $13 \cdot 9$ & $7 \cdot 7$ & 1.60 & $(0.78$ to $3 \cdot 25)$ \\
\hline \multicolumn{7}{|c|}{ Diseases of digestive system (520-577): } \\
\hline $1979-80$ & 27 & 3 & $15 \cdot 5$ & $3 \cdot 4$ & $4 \cdot 53^{\star}$ & $(1.37$ to 14.93$)$ \\
\hline $1981-3$ & 43 & 10 & $16 \cdot 6$ & $7 \cdot 6$ & 1.94 & $(0.96$ to 3.89$)$ \\
\hline $1984-6$ & 41 & 19 & $15 \cdot 9$ & $14 \cdot 8$ & 1.03 & $(0.59$ to 1.79$)$ \\
\hline \multicolumn{7}{|c|}{ Diseases of musculoskeletal system (710-738): } \\
\hline 1979-80 & 9 & 3 & $5 \cdot 1$ & $3 \cdot 4$ & $1 \cdot 49^{\star}$ & $(0.40$ to 5.52$)$ \\
\hline $1981-3$ & 17 & 5 & $6 \cdot 5$ & $3 \cdot 8$ & $1 \cdot 35$ & $(0.49$ to 3.69$)$ \\
\hline & 23 & 9 & $8 \cdot 8$ & 6.9 & $1 \cdot 25$ & $(0.57$ to 2.73$)$ \\
\hline \multicolumn{7}{|c|}{ Accidents and other effects of external causes (800-999): } \\
\hline $1979-80$ & 40 & 16 & $23 \cdot 1$ & $18 \cdot 5$ & $1 \cdot 33$ & $(0.74$ to 2.38$)$ \\
\hline $1981-3$ & 34 & 30 & $13 \cdot 0$ & $23 \cdot 5$ & 0.58 & $(0.35$ to 0.95$)$ \\
\hline $1984-6$ & 36 & 38 & $13 \cdot 9$ & $30 \cdot 2$ & $0 \cdot 46$ & $(0.29$ to 0.74$)$ \\
\hline
\end{tabular}

$\star$ Not age adjusted.

digestive system occurred considerably more often in the study group than in the control group. The difference disappeared in the subsequent phases as the control group increased its rate from 3.4 to $14 \cdot 8$, while the admission rate remained unchanged in the study group. In the phase after the closure the relative risk was $1 \cdot 03$. Admissions for all musculoskeletal diseases took place in all three phases and overall were slightly more common in the study group than in the control group. The relative risk fell during the three phases from 1.49 to $1 \cdot 25$.

Admissions for accidents and other external causes showed the greatest change associated with the closure. The admission rate in the study group fell from $23 \cdot 1$ to 13.9 compared with an increase in the control group from $18 \cdot 5$ to $30 \cdot 2$. The relative risk fell from $1 \cdot 33$ to $0 \cdot 46$. The changes for this diagnostic group may explain a considerable part of the changes in the overall admission pattern for the two groups. Admissions to somatic hospitals due to mental disorders were not included in the table as only one admission occurred in the control group in the phase after the closure. In the study group five, eight, and 12 men were admitted to hospital for mental disorders during the three phases respectively. Most admissions were related to alcohol abuse.

\section{Discussion}

Although the size of the study population, which was followed over eight years, was fairly large, the estimates of relative risk of admission were uncertain because the numbers of men admitted to hospital in the individual diagnostic groups in the three phases were rather small. A further problem was the larger number of non-responders in the study group than in the control group. Normally non-response would be expected to occur more often among sick people, and it would therefore be reasonable to asssume that bias resulting from non-response would have had a tendency to blur differences between the two groups. As the data surveillance authority did not allow us to collect data on, for example, mortality among non-responders we could not study empirically the importance of any nonresponse.

The results refuted our initial expectation that there would be a general increase in hospital admissions in the study group. On the contrary, the control group experienced the greater increases in admissions throughout the entire study. The explanation for the unexpected decrease in the relative risks lies primarily in the substantial drop in admissions due to accidents in the study group and an almost corresponding increase in the control group. Shipyards are dangerous places in which to work, and this fact influenced the study population's pattern of hospital admissions to such a degree that it largely accounted for the different trends in the two groups.

Regarding our expectation of an increase in admissions in stress related diagnostic groups after the closure the picture is less clear. The relative risk of cardiovascular diseases rose from 0.8 to $1 \cdot 6$. This tendency was even more pronounced in the diagnostic group of hypertensive disease, ischaemic heart disease, and symptomatic heart disease, in which the relative risk rose from 1.0 in the secure phase to 2.6 in the phase after closure. This increase, however, was not significant at $\mathrm{p} \leqslant 0 \cdot 05$.

The admission rate for those admitted with mental disorders was slightly increased in the study group, but we could not compare this change with that in the control group as only one admission took place during the entire study period. The rate of admissions for diseases of the digestive system was constant in the study group during the three phases whereas it increased sharply in the control group. A detailed examination of the diagnoses within the group did not indicate any specific changes, and we cannot explain this unexpected result.

The differences in the patterns of admission between the two groups do not necessarily reflect a difference in morbidity. Firstly, when men in the two groups were admitted to hospital they may have been registered differently. The guidelines for registration, however, were identical for the two groups throughout the study. Furthermore, registration was performed by hospital staff unaware of our study. Secondly, there may have been important changes - for example, the establishment or abolition of cardiology departments in the two groups' hospital districts, which would have explained the different patterns. No such changes, however, occurred. Thirdly, differences may have existed in arrangements for employed and unemployed men regarding payment for hospital services. In Denmark, however, health services are free for everyone. There are no special insurance schemes that are discontinued in the event of job loss as in the United States, where up to half of unemployed people lose their health insurance schemes because they were linked to their former jobs. ${ }^{16}$ Fourthly, behavioural differences may have occurred between the two groups. Men in the study group might have had a different 
reaction to cardiovascular symptoms than those in the control group - for example, some may have requested admission to a hospital. This also seems unlikely as it would have led to a general increase in admissions in several other diagnostic categories.

In the light of these considerations it seems reasonable to interpret the changes that took place in the patterns of admission as an impact on health resulting from reactions to the closure. The study showed changes in the weighting of the individual diagnostic groups with a fall in the number of accidents and a small rise in cardiovascular diseases. These may have been a result of changes in the study group's living conditions - from being characterised by a high risk work environment to psychosocial stresses associated with closure, job insecurity, job changes, and unemployment.

We thank Ms Anne Haastrup for typing the manuscript; Ms Vicki Carpenter Erickson and Ms Inge Olsen for translating it; and Professor Gavin Mooney for many helpful comments. The study was supported by grants $12-4218$ and 14-3616 from the Danish Medical Research Council and the Danish Social Science Research Council and grant 11/30-80 from the Danish Sickness Insurance Health Fund.

1 Jenkins R, MacDonald A, Murray J, Strathdee G. Minor psychiatric morbidity and the threat of redundancy in a professional group. Psychol Med 1982:12:799-807.

2 Brenner SO, Arnetz BB, Levi L, Petterson IL. Individual effects of job loss and unemplovment. Stockholm: Deparment of Stress Research, Karolinska Institute, 1988. (Stress Research Reports.)

3 Iversen L, Sabroe S. Psychological wellbeing among unemployed and conplo of Social Issues 1988:44:141-52.

Kasl SV, Cobb S. The experience of losing a job: some effects on cardiovascular functioning. Psychother Psychosom 1980;34:88-109.

Arnetz BB, Wasserman J, Petrini B, et al. Immune function in unemployed women. Psychosom Med 1987;49:3-12.

6 Beale N, Nethercott $S$. Job-loss and family morbidity: a study of a factory closure. F R Coll Gen Pract 1985;35:510-4.
colle

7 Beale N, Nethercott S. The nature of unemployment morbidity. 2. Description. $\mathcal{F} R$ Coll Gen Pract 1988;38:200-2.

8 Westin S, Schlesselman JJ, Korper M. Long-term effects of a factory closure: unemployment and disability during ten years' follow-up. Journal of Clinical Epidemiology 1989;42:435-41.

9 Iversen L, Sabroe S. Plant closure, unemployment and health: Danish experiences from the declining ship-building industry. In: Schwefel D, Svensson P-G, Zöllner $\mathrm{H}$, eds. Unemployment, social vulnerability, and health in Europe. Berlin: Springer-Verlag, 1987:31-47.

10 Sabroe S, Iversen L. Unemployment, social support, psychological well being, and psychosomatic symptoms. In: Starrin B, Svensson P-G, Wintersherger H, eds. Unemplomment, proerty and quality of working life. Berlin: Edition H, eds. Unemployment

11 Cook DG, Cummins RO, Bartley MJ, Shaper AG. Health of unemployed middle-aged men in Great Britain. Lancet 1982; i: 1290-4.

12 Moser KA Fox AJ Jones DR. Unemployment and mortality in the OPCS longitudinal study. Lancet 1984; ii:1324-8.

13 Iversen L, Andersen $\mathrm{O}$, Andersen PK, Christoffersen $\mathrm{K}$, Keiding $\mathrm{N}$. Unemployment and mortality in Denmark, 1970-80. Br Med J 1987;295: $879-84$.

14 Siegrist J, Siegrist K, Weber J. Sociological concepts in the aetiology of chronic disease: the case of ischaemic heart disease. Soc Sci Med 1986;22: $247-53$.

15 Breslow NE, Day NE. Statistical methods in cancer research. Vol II. The design and analysis of cohort studies. Lyons: International Agency for Research on Cancer, 1987

16 Berki SE, Wyszewianski L, Lichtenstein R, et al. Health insurance of the unemployed. Med Care 1985;23:847-54.

(Accepted 11 August 1989)

\title{
Role of community pharmacies in prevention of AIDS among injecting drug misusers: findings of a survey in England and Wales
}

\author{
Alan Glanz, Clare Byrne, Paul Jackson
}

\section{Abstract}

Objective-To determine the current and potential roles of community pharmacists in the prevention of AIDS among misusers of injected drugs.

Design-Cross sectional postal survey of a one in four random sample of registered pharmacies in England and Wales.

Setting-Project conducted in the addiction research unit of the Institute of Psychiatry, London.

Subjects - 2469 Community pharmacies in the 15 regional health authorities in England and Wales.

Main outcome measures-Willingness of pharmacists to sell injecting equipment to known or suspected misusers of drugs; pharmacists' attitudes to syringe exchange schemes, keeping a "sharps" box for use by misusers of drugs, and offering face to face advice and leaflets; and opinions of community pharmacists on their role in AIDS prevention and drug misuse.

Results-1946 Questionnaires were returned, representing a response rate of $79 \%$. This fell short of the target of one in four pharmacies in each family practitioner committee area in England and Wales, and total numbers of respondents were therefore weighted in inverse proportion to the response rate in each area. The findings disclosed a substantial demand for injecting equipment by drug misusers. After weighting of numbers of respondents an estimated 676 of 2434 pharmacies were currently selling injecting equipment and 65 of $2415(3 \%)$ were participating in local syringe exchange schemes; only 94 of 2410 pharmacies $(\mathbf{4 \%})$ had a sharps box for used equipment. There was a high degree of concern among pharmacists about particular consequences of drug misusers visiting their premises, along with a widespread acceptance that the community pharmacist had an important part to play.

Conclusions-Promoting the participation of community pharmacists in the prevention of AIDS among misusers of injected drugs is a viable policy, but several problems would need to be overcome before it was implemented.

\section{Introduction}

An important role for the community pharmacy (high street chemist) has been identified by bodies considering policy on AIDS and misuse of drugs. ${ }^{12}$ Needle sharing among drug addicts is a key factor in the spread of HIV infection. ${ }^{34}$ Several studies have found that the most common reason reported for needle sharing is lack of availability of injecting equipment. ${ }^{56}$ The supply of sterile needles and syringes is thus a crucial issue in AIDS prevention.

Several pilot "syringe exchange" schemes in varying institutional forms were launched in England and Scotland by the government in the spring of $1987 . .^{7} \mathrm{~A}$ policy of promoting the participation of pharmacies in the sales of needles and syringes has now been adopted by the government in relation to Scotland. ${ }^{8}$ In 1986 the Royal Pharmaceutical Society revised its restrictive policy on the sale of needles and syringes in the light of knowledge of the association of the spread of AIDS with sharing of injecting equipment. Now pharmacists should "exercise professional discretion each time a request for syringe or needles is made."

There is little evidence about the pattern of response among community pharmacists. This study therefore aimed at providing a picture for England and Wales of 